\title{
Correlates of Alcohol Consumption, Drug Usage, Sexual Behaviors, and Knowledge About HIV/AIDS Infection Among Traditional College Students
}

\author{
Terence Hicks, Juanita Ashby Bey, Leontye Lewis, J. Michael Harpe, and Francis Keane
}

This study evaluated the correlates of alcohol consumption, drug use, sexual behaviors, and knowledge about HIV/AIDS infection among traditional college students attending a university in North Carolina. A Health Behaviors, Self-Rated Health and Quality of Life (QOL) questionnaire was administered to 447 university students. The participants in this study were all identified as traditional college students between the ages of 18 and 23, most of whom were first-year African American students.

Results from this study determined significant relationships between alcohol consumption, drug use, protective behaviors, and having sexual intercourse among traditional college students. Most importantly, this study documented statistically significant relationships between "how often a person consumed alcohol and sexual intercourse" $[r(441)=.-325, p<.001]$, "the amount of alcohol consumed on each occasion and sexual intercourse" $[r(444)=.-207, p<.001]$, "using a condom during sexual intercourse and the number of times a person consumed alcohol," $[r(439)=.-196$, $p<.001]$, and "using protection without any alcohol or drug influences," [r(394) =.-742, $p<.001]$. Findings are discussed in terms of their implications on future research and prevention programming.

Note: This study was supported by Grant Number P20 MD001089 from the National Center of Minority Health and Health Disparities, National Institutes of Health. Its contents are solely the responsibility of the authors and do not necessarily represent the official views of National Institutes of Health.

Dr. Terence Hicks (thicks@uncfsu.edu) is Chairperson and Associate Professor of Research in the Department of Educational Leadership at Fayetteville State University (NC). He teaches statistics, quantitative research, and research methods and serves as a dissertation chair for students in the doctoral program at FSU.

Dr. Juanita Ashby Bey (jashby-bey@coppin.edu) is an Assistant Professor and Coordinator of Elementary Education at Coppin State University (MD).

Dr. Leontye Lewis (llewis8@uncfsu.edu) is Professor and Dean of the School of Education at Fayetteville State University (NC).

J. Michael Harpe is a doctoral candidate in the Educational Leadership program at Fayetteville State University (NC).

Dr. Francis Keane (fkeane@uncfsu.edu) is an Assistant Professor in the Department of Educational Leadership at Fayetteville State University (NC). He teaches research methodology courses, educational psychology, and human growth and development courses. 
Each year approximately 1,400 fatalities, 500,000 unintentional injuries, and 70,000 sexual assaults are attributed to college alcohol abuse (Hingson, Heeren, Zakocs, Kopstein, \& Wechsler, 2002). According to the Substance Abuse and Mental Services Administration (2003), full-time college students (18.8\%) aged 18 to 22 were more likely to engage in heavy drinking than their non-college peers $(13.4 \%)$. Research has indicated that alcohol is the most widely used drug on campuses, with the vast majority of students reporting use in the past year and a significant minority reporting binge drinking in the past 2 weeks. Marijuana is the second most popular drug on campuses, with between $26 \%$ and $44 \%$ of students reporting use in the past 12 months (Meilman, Stone, Gaylor, \& Turco, 1990; Presley, Meilman, \& Lyerla, 1993). According to Presley, Meilman, and Lyerla, this high level of substance use is worrisome because it is largely illegal and because it is associated with negative consequences such as poor grades, driving under the influence, and physical injury.

Surprisingly, studies examining the health behaviors of minority populations, specifically African American college students, are relatively rare. In one peculiar study of this population of college students, drinking patterns of Black college students were found to be characterized as light to moderate, with a limited amount of heavy drinking (Thurston, 1982).

In another campus-wide survey of Black college students, $77.8 \%$ of the respondents reported drinking alcohol. Of those students, $19.2 \%$ drank weekly, $39.6 \%$ drank monthly, $28.4 \%$ drank one to two times a year, and $12.8 \%$ drank less than once a year (Ford \& Carr, 1990). In a more recent study, Wagner, Liles, Broadnax, and Nuriddin-Little (2006) reported that among Historically Black Colleges and Universities (HBCUs) undergraduate students, 42\% of students previously used marijuana, 19\% smoked tobacco, and 11\% reported use of other people's prescription drugs. These authors found that the drug of choice for the participating cohort was alcohol; their data indicated that $83 \%$ of the students at some point in their lives consumed alcohol, and 51\% currently continued its use.

In addition, Wagner, Liles, Broadnax, and Nuriddin-Little noted that approximately $41 \%$ of the students reported marijuana use at some time in their lives and more than 33\% indicated marijuana use during the month preceding data collection for their study, and $44 \%$ of the students living in dormitories also had used marijuana in the preceding month. The study's authors found that other people's prescriptions were the next most frequently used illegal drugs, with a rate of $11 \%$ and a recent use rate of $4 \%$ among students with a history of illegal drug use. Almost 45\% of drug-experienced students reported that they used drugs "to get high," and over $42 \%$ reported drug use "to celebrate."

Researchers continue to study college students' knowledge and attitudes about HIV/AIDS because of heightened risk of infection associated with new found independence, peer pressure to experiment with sexual activity and drugs, and feelings of invincibility (Gayle, et al., 1990). Predictably, many institutions try to educate students about HIV/AIDS because of the affirmed relationship between increased knowledge and more positive attitudes toward AIDS victims (James \& Frese, 1993) and homosexuals (Ramsum, Marion, \& Mathias, 1993).

According to the Centers for Disease Control and Prevention (1994), African 
Americans represent a major proportion of all documented AIDS cases in the United States among racial and ethnic minorities. More alarming, HIV prevalence among youths ages 16 to 21 years who entered the Job Corps $(N=269,956)$ was highest among African Americans compared with other ethnic groups (Conway, et al., 1993). However, studies have suggested that one well-documented behavior deemed important to reducing HIV risk is consistent use of condoms.

Jemmott and Jemmott (1990) reported that consistent condom use was reported by only one fifth of sexually active, urban, African American male adolescents. Crawford (1990) noted that only 31\% of African American students surveyed reported use of condoms during coitus. Johnson, Hinkle, Gilbert, and Gant (1992) concluded that 29\% of 106 African American men did not use condoms or reported low intentions to use condoms. Biggar, Brinton, and Rosenthal (1989) found that African American women (mean age 46.4, range 21 to 72 years) tend to have a higher mean number of sexual partners and typically are sexually active at an earlier age than are White women (mean age 43.7, range 20 to 71). According to Johnson, Gant, Hinkle, Gilbert, Willis, et al., (1992), even well-educated African American college students who engage in risky sexual practices display the tendency to deny their vulnerability to HIV infection.

During the last decade, mental health research on minority college students has demonstrated that the success of an orientation program has become a significant factor in impacting student retention. The literature presented on alcohol consumption, drug use, sexual behaviors, and HIV/AIDS suggests that there is a need for college orientation and transition staff to convey prevention information early in the freshmen orientation process for young African American adults. Therefore, the purpose of this study was to conduct a baseline investigation of traditional college students' alcohol consumption, drug use, sexual behavior, and lack of knowledge about HIV/AIDS infection. The results of this study may be useful in identifying certain subgroups of students at particular risk for certain types of lifestyle patterns while attending college. In addition, this study imparts background information that may be helpful in providing alcohol, drug, and unsafe sexual behavior prevention programs and literature for incoming first-year traditional college students.

\section{Method}

\section{Participants}

The Health Behaviors, Self-Rated Health, and Quality of Life (QOL) questionnaire was administered to 447 university students during the Fall 2005/Spring 2006 academic semesters. The participants in this study were all identified as traditional college students between the ages of 18 and 23, most of whom were African Americans (63.5\%). Sixty-four percent of the sample was female and comprised of approximately $58.8 \%$ freshmen, $14.8 \%$ sophomores, $16.6 \%$ juniors, $9.2 \%$ seniors, and $0.6 \%$ graduate students. As far as living 
conditions, $71 \%$ of the college students indicated that they were living on-campus and $29 \%$ lived off campus. Ninety percent of the study sample comprised of residents of North Carolina. Fifty-one percent of the participants were firstgeneration college students. A majority of the college students $(43.2 \%)$ in this study indicated that they received student loans and support from their spouse or parents, $18.3 \%$ indicated that they received student loan and income from paid employment, $19.7 \%$ indicated that they received student loans and other sources of income, and 9.4\% indicated they only received student loans.

\section{Procedure}

Students who were enrolled in Fall 2005 and Spring 2006 courses at a participating 4-year public North Carolina university completed the QOL. After obtaining permission from the university Institutional Review Board (IRB), professors of both upper and lower level courses were contacted for an agreeable time to administer the survey. Before completing the survey, students signed an Informed Consent form. Each QOL answer sheet was assigned a number and entered into SPSS. Completed data sheets and signed consent forms were kept in separate locked cabinets.

\section{Instrument}

The 30-item questionnaire used in this study was the Health Behaviors, Self-Rated Health and Quality of Life (Vaez \& Laflamme, 2004), also known as the Quality of Life (QOL) survey. Six additional questions that addressed sexual behaviors and drugs were created by the study authors of this study and added to the original 30-item questionnaire. In addition, a demographic section which included questions related to, for example, age, sex, race, and living conditions, was added to the QOL questionnaire. The original QOL sections also included Life-Style, Student Life Stressors, and Health Status.

The questionnaire assessed health behavior variables such as frequency of alcohol consumption (never, once a month, 2-4 times a month, 2-3 times a week, 4 times a week or more) and the typical amount of alcohol consumed on each occasion (1-2 glasses, 3-4 glasses, 5-6 glasses, 7-9 glasses, 10 glasses or more). To answer questions about cigarettes smoked, participants' response choices were "yes, daily;" "yes, sometimes;" or "no." Physical activity was assessed with a single question concerning the frequency of exercise on a 5-point scale (never, once a month, 2-4 times a month, 2-3 times a week, and 4 times a week or more). To answer questions related to life stressors over the preceding academic year, students chose between responses based on a 4-point scale (not at all stressed, slightly stressed, rather stressed, highly stressed). To answer questions related to perceived health status and quality of life, students rated their physical, psychological, and overall health respectively on a 5-point scale (very good, good, neither good nor poor, poor, very poor). To measure psychological or 
psychosomatic problems, students responded to a 4-point scale (not at all, a little, quite a lot, and a lot).

Three questions were "ladder questions." A ladder question typically is introduced the following way: "Here is a picture of a ladder. At the bottom of the ladder, 1 is the worst life you might reasonably expect to have, and 10 at the top is the best life you might reasonably expect to have. Indicate where on the ladder your life is right now." According to Vaez and Laflamme (2004), this "ladder scale" is a widely recognized measure that has shown good validity. To answer questions about ever talking about HIV/AIDS infection with parents or other adults in the family or ever taught about HIV/AIDS infection in any college courses, participants' response alternatives were "yes," "no," or "not sure." To answer the question about ever having sexual intercourse, response choices were "yes," or "no." To answer questions about the usage of alcohol or drugs before having sexual intercourse, and whether the participant used a condom the last time he or she had sexual intercourse, response choices were "yes," "no," or "never had sexual intercourse." To answer the question about what one method did the participant or his or her partner use to prevent pregnancy during last sexual intercourse, response alternatives were, "have never had sexual intercourse," "no method," "birth control pills," "condom," "diaphragm or sponge," "withdrawal," "some other method," and "not sure."

\section{Results and Discussion}

\section{Alcohol Consumption, Drugs Usage, and Sexual Intercourse Among Traditional College Students}

A Pearson correlation coefficient was calculated for the relationship between drinking alcohol and using drugs before having sexual intercourse. As seen in Table 1, a moderate correlation was found $[r(441)=-.325, \mathrm{p}<.001]$ between sexual intercourse and how often a person drinks alcohol. However, a weak correlation was found $[r(444)=-.207, \mathrm{p}<.001]$ between sexual intercourse and the amount consumed on each occasion. According to Cooper (2002), research examining the link between alcohol and risky sex at the global level typically asks participants about their overall involvement in some high-risk behavior and their overall frequency and quantity of alcohol use. Studies using this approach have generally found strong relationships between alcohol use and indiscriminate behaviors, but inconsistent ones between alcohol use and protective behaviors. However, what is apparent is that studies have indicated that most college students are sexually experienced and many engage in multiple forms of risky sexual behavior.

Surprisingly, showing negative moderate and weak relationships between sexual intercourse/how often a person drinks alcohol and sexual intercourse/the amount of alcohol consumed on each occasion, the findings may be alarming and eye opening for this sample of traditional college students. According to 
Wagner, Liles, Broadnax, and Nuriddin-Little (2006), undergraduate alcohol use and other drug use poses particular concerns for students and their families, college and university personnel and administration, and for society at large. Educational difficulties; antisocial behavior, including damage to private and public property; psychosocial and legal problems; and poor behavioral choices such as sexual risk-taking and driving while under the influence of alcohol or other drugs have been associated with problematic alcohol and other drug use, as have poor educational and professional outcomes (Wechsler, Lee, Kuo, \& Lee, 2000; Wagner, 1989).

A weak correlation was also found $[r(439)=-.196, \mathrm{p}<.001]$ between using a condom during sexual intercourse and the number of times a person drank alcohol. However, it was interesting to note that when looking at college students' health behaviors toward having sex and using protection without any alcohol or drug influences, a very strong correlation was found $[r(394)=.742, \mathrm{p}<.001]$. As seen in Table 2, this finding was consistent with the responses from question 36 ("the last time you had sexual intercourse, what one method did you or your partner use to prevent pregnancy") where majority of the college students (38.8\%) indicated that they used a condom, followed by using birth control (25.9\%).

TABLE 1

\section{Correlation Matrix for Alcohol Consumption, Drug Usage and Sexual Intercourse}

Variable

Question $10 \quad$ Question 11

How often do you drink? Amount Consumed?

Question 33

Have you ever had sexual intercourse? $.176^{* *}$

Question 34

Did you drink alcohol or use drugs

before you had sexual intercourse?

Question 35

The last time you had sexual intercourse, did you use a condom? $\quad-.196^{* *}$

\footnotetext{
** Correlation is significant at the 0.01 level (2-tailed).
} 
The weak relationship found between alcohol consumption and protective behavior (condoms) in this study is somewhat consistent with other studies. According to Cooper (2002), studies examining the correlation between drinking prior to intercourse and decreased protective behaviors (i.e., condom and birth control use) reveal a weaker link. Cooper indicates that the overwhelming majority of studies, whether examining global or situation specific associations, found no effect whatsoever. Cooper notes that the primary exceptions to this pattern were found for younger, sexually inexperienced adolescents and for sexual events occurring during or prior to 1990. Thus, these findings mirror other studies and suggest that the link between alcohol use and protective behavior may be both developmentally and historically limited.

TABLE 2

\section{Sexual Intercourse and Method of Protection}

\section{Question}

36. The last time you had sexual intercourse, what one method did you or your partner use to prevent pregnancy?

$\begin{array}{lr}\text { Have never had sexual intercourse } & 17.6 \% \\ \text { No method } & 6.7 \% \\ \text { Birth control pills } & 25.9 \% \\ \text { Condom } & 38.8 \% \\ \text { Diaphragm or sponge } & 0 \% \\ \text { Withdrawal } & 5.1 \% \\ \text { Some other method } & 2.5 \% \\ \text { Not sure } & 3.4 \%\end{array}$

Table 3 examines the frequency of alcohol consumed (never, once a month, 2-4 times a month, 2-3 times a week, 4 times a week or more) and the typical amount of alcohol consumed on each occasion by each student in the study (1-2 glasses, 3-4 glasses, 5-6 glasses, 7-9 glasses, 10 glasses or more). A majority of college students (38.9\%) indicated that they "never" drink alcohol, 23.3\% indicated that they drink "once a month," 26.8\% indicated that they drink "2-4 times a month," 8.7\% indicated that they drink "2-3 times a week," and 2.3\% indicated that they drink "4 times a week or more." Also shown in Table 3, when asked, "If you did drink, what is the usual amount consumed on each occasion," a majority of the college students (28.9\%) indicated that they consumed 1-2 glasses on each occasion, $19.7 \%$ consumed 3-4 glasses on each occasion, $13.0 \%$ consumed 5-6 glasses on each occasion, 2.9\% consumed between 7-9 glasses on 
each occasion, and $1.8 \%$ noted that they consumed 10 glasses or more on each drinking occasion.

These percentages found on this sample of college students were somewhat surprising. A 61.1\% current prevalence (past 30 days) of alcohol use was found, which is higher than the current prevalence rate found in the national sample group of 18 to 20 year olds in 2002 (approximately 50\%). However, the percentage rate $(61.1 \%)$ was lower than the 21 to 25 age group (approximately $67 \%$ ), including the peak at age 21 (70.9\%). In fact, this rate was even lower than the current prevalence among American college students (70\%) in 1999. The data from a more recent study conducted on African American college students shows that the $61.1 \%$ current prevalence of alcohol usage percentage rate was higher than the percentage rate found in Wagner, Liles, Broadnax, and Nuriddin-Littles' (2006) study; these authors found that $83 \%$ of the students in their study at some point in their lives consumed alcohol and 51\% currently continued its use. In addition, the authors found that fewer than $10 \%$ of students reported any experimentation with cocaine, crack, hallucinogens, uppers, downers, inhalants, opiates, designer drugs, prescription drugs, and over-the-counter substances with high alcohol content for non-medical reasons. In fact, Wagner, et al. (2006) relayed that their study results appeared to indicate that the majority of students believed they used alcohol as a part of their celebration rituals and as a way to "fit in" with others.

Specific to alcohol and drug use among college students attending historically Black universities, Ford and Goode (1994) surveyed the health behaviors of 224 undergraduate students enrolled in health education classes. The rate of cigarette smoking among these students was low (4\%), with more men than women reporting this behavior. More recently, however, Hicks and Miller (2006) reported that among first-year and non-first-year African American college students attending a historically Black university, only about $4 \%$ of all students reported smoking on a daily basis, with 45\% $(n=230)$ first-year and 40.2\% $(n=204)$ non-first-year students reporting not smoking at all. Only 9 first-year and 7 nonfirst-year students reported using illegal drugs on a daily basis. Among all students, illegal drug use (daily and sometimes) was $6.05 \%$, with $45.6 \%$ of first-year and $42.3 \%$ of non-first-year reporting never using illegal drugs.

In contrast to Ford and Goode (1994) and the findings in the Hicks and Miller (2006) study on the low percentage of African American students who smoke cigarettes and use illegal drugs, Powe and Finnie (2005) found that as many as $18 \%$ of African American college students smoke. These authors' findings are more in line with the results from this current study on 18 to 24 year old college students. As seen in Table 3, students in this study reported that they smoke cigarettes or use illegal drugs (daily and sometimes) at $20.1 \%$ and $16.9 \%$ respectively. This percentage is similar to the findings by the U.S. Department of Health and Human Services (1999) which reported that an average of $16.1 \%$ college students aged 18 to 25 engaged in illicit drug use. Moreover, these findings contribute to the identification of subgroups of students who are at particular risk for certain types of drug and health issues that can be addressed by university officials and health and wellness personnel by implementing 
appropriate interventions that are tailor-made for such groups. University officials and administrators along with health prevention specialists could help in addressing health issues among traditional African American college students by meeting national health goals and eliminating the health status disparities by implementing effective programs.

\section{TABLE 3}

\section{Summary of Alcohol Consumption and Drugs Among Traditional College Students}

\section{Question}

10. How often do you drink alcohol?

Never

Once a month

2-4 times a month

2-3 times a week

4 times a week or more
$38.9 \%$

$23.3 \%$

$26.8 \%$

$8.7 \%$

$2.2 \%$

11. If you do drink, what is the usual amount consumed on each occasion?

$\begin{array}{lr}1-2 \text { glasses } & 28.9 \% \\ 3-4 \text { glasses } & 19.7 \% \\ 5-6 \text { glasses } & 13.0 \% \\ 7-9 \text { glasses } & 2.9 \% \\ 10 \text { glasses or more } & 1.8 \%\end{array}$

12. Do you smoke cigarettes?

$\begin{array}{lr}\text { yes, daily } & 8.7 \% \\ \text { yes, sometimes } & 11.4 \% \\ \text { no } & 79.9 \%\end{array}$

13. Do you use illegal drugs?

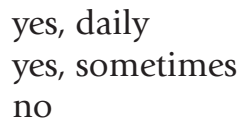




\section{Knowledge about HIV/AIDS Infection among}

\section{Traditional College Students}

Recent studies have indicated that college students have very good to excellent levels of knowledge regarding the HIV virus and AIDS, with students knowing what HIV and AIDS are, how HIV is transmitted, and how to prevent the transmission of the virus (Keeling, 1991; Grieger \& Ponterotto, 1988; McDermott, Moore, \& Cittadina, 1987). Table 4 shows that a larger percentage of college students (59.5\%) indicated yes, they talked about HIV/AIDS with their parents or other adult from their family. In question, again a larger percentage of students (59.5\%) indicated yes, they were taught about HIV/AIDS infection in their college courses. These findings on knowledge about HIV/AIDS with the present group of college students could be rewarding, but knowledge alone can not guarantee safer sexual practices. However, researchers have commonly found that most college students are knowledgeable about HIV transmission routes and protection methods, but that knowledge rarely deters them from engaging in risky sexual practices. Mattson (2002) notes that the lack of HIV/AIDS research on college campuses results in limited knowledge about students' perceptions and safer sex behaviors and increases the difficulty of developing effective education and prevention strategies.

For question 33 ("Have you ever had sexual intercourse?") and question 35 ("The last time you had sexual intercourse, did you use a condom?"), a larger percentage of the college students responded "yes" at $80.1 \%$ and $50.3 \%$ respectively. These findings are consistent with what Davis, Sloan, MacMaster, \& Kilbourne (2007) found when examining racial differences among current sexual behaviors and safer sex practices, HIV/AIDS awareness, condom use and self-efficacy, and attitudes toward safer sex practices in a sample of U.S. college students. These authors relayed that sexually active African American students reported higher condom use and greater intentions to use either condoms or other safe sex practices in the future than the sexually active White students. However, other studies that reviewed the prevalence of alcohol and risky sex on college campuses revealed overlapping behaviors. For example, according to findings from the National College Health Risk Behavior Survey (Douglas, et al., 1997), 8 out of 10 college students between the ages of 18 and 24 have had intercourse. Of these, $62 \%$ had recent intercourse (within the past 3 months). More importantly, about $25 \%$ of students have had six or more lifetime sex partners, and only a minority takes adequate precautions to prevent pregnancy or sexual infection. For example, 4 in 10 students had used birth control pills, and about as many had used condoms during their last sexual engagement. Fewer than 4 in 10 students reported that either they or their partners had always used condoms in the past 30 days. Finally, in a national study of Canadian college students (MacDonald, et al., 1990), 17\% reported having ever had anal sex, but fewer than $25 \%$ reported always using a condom. It is evident that the above data and the data from the present study indicate that alcohol use, sexual behaviors, and not using protection are commonplace among college students. Furthermore, these studies provide 
some insight into the health and sexual behaviors of traditional African American college students. Hicks and Tang (under review) suggest ways of combating unsafe activity; the authors recommend that a comprehensive sexual education program be provided by the surrounding community, which would examine the students' sexual values and sexual behaviors. Campus peer education programs, which can provide a solid knowledge base but facilitate long-term behavior changes as well, may be an effective mechanism to deliver such information to college students.

TABLE 4.

\section{Summary of Knowledge of HIV/AIDS Infection, Sexual Behaviors, Alcohol Consumption, and Drug Use Among Traditional College Students}

\section{Question}

31. Have you ever talked about HIV/AIDS infection with your parents or other adults in your family?

$\begin{array}{lr}\text { yes } & 59.5 \% \\ \text { no } & 34.2 \% \\ \text { not sure } & 6.3 \%\end{array}$

32. Have you ever been taught about HIV/AIDS infection in any of your college courses?

$\begin{array}{lr}\text { yes } & 59.5 \% \\ \text { no } & 38.5 \% \\ \text { not sure } & 2.0 \%\end{array}$

33. Have you ever had sexual intercourse?

$\begin{array}{lr}\text { yes } & 80.1 \% \\ \text { no } & 19.0 \% \\ \text { not sure } & .9 \%\end{array}$

34. Did you drink alcohol or use drugs before you had sexual intercourse the last time?
yes
$17.7 \%$
no
$67.0 \%$
never had sexual intercourse
$15.3 \%$ 
35. The last time you had sexual intercourse, did you use a condom?

$\begin{array}{ll}\text { yes } & 50.3 \% \\ \text { no } & 31.1 \% \\ \text { never had sexual intercourse } & 18.6 \%\end{array}$

\section{Conclusion}

The results from this questionnaire provided an important snapshot of the current alcohol consumption rate, drug use, sexual behaviors, and knowledge about HIV/AIDS infection among traditional African American college students attending an institution in North Carolina. Moreover, the results contributed to the identification of subgroups of students at particular risk for certain types of health issues that university officials can address by implementing appropriate interventions that are tailor-made for such groups. While most of the findings indicated a weak relationship, a strong relationship was found when looking at first-year college students' sexual behavior and their using protection without any alcohol or drug influences.

This finding among first-year college students attending an HBCU is important. According to Hicks and Miller (2006), responses to the questionnaires from first-year students at this HBCU could help determine how the health status of students attending other HBCUs compares with some of the national objectives outlined in Healthy People 2010. Furthermore, no information is available about which health intervention or orientation programs are most effective for AfricanAmerican college students that attend HBCUs. Thus, such information is needed to better assess the potential for students not completing college due to risky health behaviors and habits, depression, and stress (Hicks \& Miller, 2006). Most importantly, as the population of college-bound students grows and competition increases, university orientation and transition professionals should keep in mind common health behavior issues, stress patterns, and at-risk demographics that affect incoming students and be proactive in planning effective intervention programs to combat these issues. As advocates for students, those in higher education must conduct further research so they can prevent future and more complex behavior problems. Researching and implementing effective intervention, counseling, and orientation programs will help improve the quality of life for everyone on campus (Hicks \& Miller, 2006).

Nonetheless, the results should be interpreted with caution. First, self-reported surveys are a form of measurement commonly used in studies of this nature and are considered reliable. However, participants may distort their survey responses and may represent a source of bias. Second, although we drew a probability sample of college students, the study included students from only one university, so special care should be taken not to generalize the findings of this study to other student populations. The findings may hold true only if the populations are similar in 
nature.

Despite these limitations, our study has several important findings and could be added to existing research on African American traditional college students. Future researchers could look at how well the self-reported alcohol, drug, and sexual behavior of traditional African-American college students and other groups are meeting the health objectives for the nation as outlined in the Healthy People 2010 publication. Furthermore, to combat alcohol, drug, and health issues among college students in the university setting, Hicks and Miller (2006) suggest that university officials and administrators, along with health prevention specialists, address health issues among African-American college students by meeting national health goals and eliminating the health status disparities by implementing effective programs. These authors note that until more accurate methods are developed to identify which students are at risk of failing and leaving college, little can be done to intervene and to help avoid undesired consequences of health issues such as poor academic performance and attrition, which affect both students and the institutions.

\section{References}

Biggar, R. J., Brinton, L. A., \& Rosenthal, M. D. (1989). Trends in the number of sexual partners among American women. Journal of Acquired Immune Deficiency Syndromes, 2(5), 497-502.

Centers for Disease Control and Prevention. (1994). HIV/AIDS Surveillance Report No. 6, 1-39.

Conway, G. A., Epstein, M. R., Hayman, C. R., Miller, C. A., Wendell, D. A., Gwinn, M., et al. (1993). Trends in HIV prevalence among disadvantaged youth. Journal of the American Medical Association, 269(22), 2887-2889.

Cooper, M. L. (2002). Alcohol use and risky sexual behavior among college students and youth: Evaluating the evidence. Journal of Studies on Alcohol, $14,101-117$.

Crawford, I. (1990). Attitudes of undergraduate college students toward AIDS. Psychological Reports, 66(1), 11-16.

Davis, C., Sloan, M., MacMaster, S., \& Kilbourne, B. (2007). HIV/AIDS knowledge and sexual activity: An examination of racial differences in a college sample. Health and Social Work. 32(3), 211-218.

Douglas, K. A., Collins, J. L., Warren, C., Kann, L., Gold, R., Clayton, S., et al. (1997). Results from the 1995 National College Health Risk Behavior Survey. Journal of American College Health, 46(2), 55-66.

Ford, D. S., \& Carr, P. G. (1990). Psychosocial correlates of alcohol consumption among Black college students. Journal of Alcohol and Drug Education, 36(1), $45-51$.

Ford, D. S., \& Goode, C. R. (1994). African American college students' health behaviors and perceptions of related health issues. Journal of American College Health, 42(5), 206-210. 
Gayle, H. D., Keeling, R. P., Garcia-Tunon, M., Kilbourne, B. W., Narkunas, J. P., Ingram, F. R., et al. (1990). Prevalence of the Human Immunodeficiency Virus among college students. The New England Journal of Medicine, 323(22), $1538-1541$.

Grieger, I., \& Ponterotto, J. G. (1988). Students' knowledge of AIDS and their attitudes toward gay men and lesbian women. Journal of College Student Development, 29, 415-422.

Hicks, T., \& Miller, E. (2006). College life styles, student life stressors and health status among African American male and female college students. Journal of College Admission, 192 (1), 22-29.

Hicks, T., \& Tang, L. (under review, 2008). Life styles, stressors and health status: Differences among on-campus and off-campus college students. Manuscript submitted for publication.

Hingson, R. W., Heeren, T., Zakocs, R. C., Kopstein, A., \& Wechsler, H. (2002). Magnitude of alcohol-related mortality and morbidity among U.S. college students ages 18-24. Journal of Studies on Alcohol, 63(2), 136-144.

James, M., \& Frese, W. (1993). AIDS: Knowledge and attitudes of college students. College Student Journal, 27(4), 402-414.

Jemmott, L. S., \& Jemmott, J. B. (1990). Sexual knowledge, attitudes, and risky sexual behavior among inner-city Black male adolescents. Journal of Adolescent Research, 5(3), 346-369.

Johnson, E. H., Gant, L., Hinkle, Y. A., Gilbert, D., Willis, C., \& Hoopwood, T. (1992). Do African-American men and women differ in their knowledge about AIDS, attitudes about condoms, and sexual behaviors? Journal of the National Medical Association, 84(1), 49-64.

Johnson, E. H., Hinkle, Y., Gilbert, D., \& Gant, L. M. (1992). Black males who always use condoms: Their attitudes, knowledge about AIDS, and sexual behavior. Journal of the National Medical Association, 84(4), 341-352.

Keeling, R. P. (1991). Time to move forward: An agenda for campus sexual health promotion in the next decade. Journal of American College Health, 40(2), 51-53.

McDermott, R. J., Hawkins, M. J., Moore, J. R., \& Cittadina, S. K. (1987). AIDS awareness and information sources among selected university students. Journal of American College Health, 35(5), 222-226.

MacDonald, N. E., Wells, G. A., Fisher, W. A., Warren, W. K., King, M. A., Doherty, J. A., et al. (1990). High-risk STD/HIV behavior among college students. Journal of American Medical Association, 263(23), 3155-3159.

Mattson, M. (2002). Impact of HIV test counseling on college students' sexual beliefs and behaviors. American Journal of Health Behavior, 26(2), 121-136.

Meilman, P. W., Stone, J. E., Gaylor, M. S., \& Turco, J. H. (1990). Alcohol consumption by college undergraduates: Current use and 10-year trends. Journal of Studies on Alcohol, 51(5), 389-395.

Powe, B., \& Finnie, R. (2005, November). Smoking behavior among African American college students: Do attitudes and beliefs matter? Paper accepted for presentation at the 133rd annual meeting of the American Public Health Association, New Orleans, LA. 
Presley, C. A., Meilman, P. W., \& Lyerla, R. (1993). Alcohol and other drugs on American college campuses: Use, consequences, and perceptions of the campus environment, 1989-1991 (Vol. 1). Carbondale, IL: Southern Illinois University at Carbondale.

Ramsum, D. L., Marion, S. A., \& R. G. Mathias. (1993). Changes in university students' AIDS-related knowledge, attitudes and behaviours, 1988 and 1992. Canadian Journal of Public Health, 84(4), 275-278.

Substance Abuse and Mental Health Services Administration. (2003). Results from the 2002 National Survey on Drug Use and Health: National findings (NHSDA Series H-22. DHHS Publication No. SMA 03-3836). Rockville, MD: Office of Applied Studies.

Thurston R. V. (1982). A sociocultural investigation of drinking patterns in a Black college population. Dissertation Abstracts International, 43(1).

U.S. Department of Health and Human Services [USDHHS]. (1999). National household survey on drug abuse: Population estimates. Rockville, MD: Public Health Service.

Vaez, M., \& Laflamme, L. (2003). Health behaviors, self-rated health, and quality of life: A study among first-year Swedish university students. Journal of American College Health, 51(4), 156-162.

Wagner, M. L. (1989). Undergraduate independent college students' use of and opinions about tobacco, alcohol, and other drug. Unpublished doctoral dissertation, University of North Carolina, Greensboro.

Wagner, M. L., Liles, R. G., Broadnax, R. L., \& Nuriddin-Little, A. (2006). Use of alcohol and other drugs: Undergraduate HBCU students. Negro Educational Review, 57(3-4), 229-242.

Wechsler, H., Lee, J. E., Kuo, M., \& Lee, H. (2000). College binge drinking in the 1990s: A continuing problem. Journal of American College Health, 48(10), 199-210. 